\title{
LA FALLA EN EL SERVICIO: UNA IMPUTACIÓN TRADICIONAL DE RESPONSABILIDAD DEL ESTADO*
}

\section{Ciro Nolberto Güechá Medina, Ph.D**}

Fecha de Recibido: 15 de septiembre de 2011

Fecha de Aprobación: 12 de diciembre de 2011

Artículo resultado de Investigación

\begin{abstract}
Resumen
La Responsabilidad por falla del Estado, es el título de imputación de mayor relevancia dentro del ordenamiento jurídico colombiano, en cuanto que las actuaciones irregulares de la administración generadoras de perjuicios, se han convertido en el criterio usual de responsabilidad administrativa.

En efecto, no ha sido la responsabilidad objetiva sino la responsabilidad por falla la de mayor tradición, con fundamento en que los principios de legalidad y de buen servicio público son vulnerados dentro de la actuación de las entidades públicas; lo que significa, que el Estado se ha convertido en el principal transgresor del ordenamiento jurídico, ya que en la falla del servicio, de una u otra manera, lo que existe es una violación de normas que protegen derechos de los particulares.

Por lo anterior, en el presente artículo se realiza un estudio doctrinal, jurisprudencial y de derecho comparado de la responsabilidad administrativa del Estado por falla en el servicio, de manera que se expondrá su evolución y la situación actual de la misma
\end{abstract}

\section{Palabras clave}

Responsabilidad, falla, servicio, administración, irregularidad, antijuridicidad, daño.

\section{THE FAILURE OF THE SERVICE: A TRADITIONAL ATTRIBUTION OF RESPONSIBILITY OF STATE}

\begin{abstract}
Responsibility of States for failure, is the title of most relevant complaint within the Colombian legal system, in that improper conduct by management generating losses, have become usual in the criteria of administrative responsibility.
\end{abstract}

* Resultado de investigación Responsabilidad del Estado por actos terroristas. Grupo de investigaciones jurídicas y sociojurídicas de la Universidad Santo Tomás de Tunja. Director Ciro Güechá Medina

** Docente investigador de la Universidad Santo Tomás de Aquino de Tunja, líder del grupo de investigación en Derecho Administrativo de La Universidad Santo Tomás de Aquino de Tunja de la Facultad de Derecho, correo electrónico cguecha@ustatunja.edu.co; ciroguecha@hotmail.com 
Indeed, it was not strict liability, but fails responsibility for most traditional, based on the principles of legality and good public service are violated in the performance of public entities, which means that the State has become a major violator of the law, because in the blackout, one way or another, so there is a violation of rules to protect rights of individuals.

Therefore, in this paper makes a study of doctrine, jurisprudence and comparative law of the State administrative responsibility for service failure, so as to expose its evolution and current status of the same.

\title{
Keywords
}

Responsibility, fault, service, administration, irregularity, illegality, injury.

\section{A FALHA DO SERVIÇO: A ATRIBUIÇÃO TRADICIONAL DE RESPONSABILIDADE DO ESTADO}

\begin{abstract}
Resumo
Responsabilidade de Estados para falha, é o título de queixa mais pertinente dentro do sistema legal colombiano, naquela conduta impropia pela administração que gera perdas, aconteceu habitualmente nos critérios de responsabilidade administrativa.

$\mathrm{Na}$ verdade, não era responsabilidade objetiva, mas não a responsabilidade pela mais tradicional, com base nos princípios da legalidade e bom serviço público são violados no desempenho das entidades públicas, o que significa que o Estado tornou-se um grande violador da lei, porque em o apagão, de uma forma ou de outra, para que haja uma violação de regras para proteger os direitos dos indivíduos.

Portanto, neste trabalho faz um estudo da jurisprudência, doutrina e de direito comparado sobre a responsabilidade do Estado por falha no serviço administrativo, de modo a expor a sua evolução e estado actual da mesma.
\end{abstract}

\section{Palavras-chave}

Responsabilidade, culpa, serviço, administração, irregularidade, ilegalidade lesão.

\section{INTRODUCCIÓN}

Con el presente artículo, se pretende analizar la institución de la falla del servicio en el sistema jurídico colombiano y sus referencias en el derecho comparado, específicamente en el derecho español y el derecho francés, los sistemas más próximos a dicha institución.
En las anteriores circunstancias, el estudio se realizará a partir de los orígenes clásicos de la teoría en el ordenamiento jurídico galo, la cual es eminentemente pretoriana, cuando las decisiones del Consejo de Estado Francés le dieron inicio y consolidación, para pasar al análisis de la institución en nuestro ordenamiento y culminar con las referencias españolas de este título de imputación. 
No es el fruto de extensas regulaciones legales, por el contrario, ha sido la jurisprudencia quien la ha moldeado, a pesar que existen normas constitucionales y del Código Civil, a la par que algunas de Derecho Público que la determinan; por esta razón, el análisis jurisprudencial y doctrinario será de vital importancia, para conocer la realidad del título de imputación de responsabilidad más conocido y utilizado por los jueces de la administración.

\section{LA FALLA DEL SERVICIO TIENE SUS ORÍGENES EN LA TEORÍA CLÁSICA DEL DERECHO ADMINISTRATIVO FRANCÉS}

La noción de falla ha sido tradicional en el ordenamiento jurídico colombiano, en cuanto que las actuaciones irregulares de la administración se han considerado el criterio sustancial para atribuir responsabilidad a la misma por su actividad'; el cual no es propio del Derecho Administrativo Colombiano, sino que tiene sus antecedentes en el sistema jurídico francés.

En efecto, la teoría clásica francesa de responsabilidad del Estado se ha referido a esta clase de responsabilidad, como fundamento de la obligación de la administración de indemnizar los perjuicios causados, con ocasión de la actuación de las entidades públicas, en cuanto que en la

1 *Resultado de investigación Responsabilidad del Estado por actos terroristas. Grupo de investigaciones jurídicas y sociojurídicas de la Universidad Santo Tomás de Tunja. Director Ciro Güechá Medina

** Ciro Nolberto Güechá Medina, es docente investigador de la Universidad Santo Tomás de Aquino de Tunja, líder del grupo de investigación en Derecho Administrativo de La Universidad Santo Tomás de Aquino de Tunja de la Facultad de Derecho, correo electrónico cguecha@ustatunja.edu.co

Es preciso indicar, que hay casos en que el Estado no ha actuado, es decir, no ha generado con su actuación el daño, sin embargo debe concurrir a la indemnización del perjuicio, con fundamento en un título de imputación estrictamente jurídico y no material; sin que se quiera decir, que los eventos de imputación material no sean jurídicos, en el sentido de asignación de responsabilidad. misma se evidencia irregularidad, es decir, una persona jurídica estatal sujeta a error (Saavedra, 2005, p. 231)2 en el entendido que la misma actuaba a través de sus agentes o servidores, pero que la actividad era atribuible a la ente público, por no ser posible separarlo del servicio público, de la actividad administrativa (Depuis, 2004, p. 56)³.

Y si la responsabilidad por falla ha de considerarse como actuación irregular de la administración, es decir, reprochable no solo social sino jurídicamente, es preciso afirmar, que debemos identificarla con la culpabilidad, por cuanto en esta se evidencian las formas de actuación irregular de la administración a que se hecho referencia (Paillet, 2001, p. 114)4.

2 SAAVEDRA BECERRA, RAmIRO, La Responsabilidad Extracontractual de la Administración Pública, tercera reimpresión, Bogotá Colombia, Ediciones Jurídicas Gustavo Ibáñez, 2005, p.231. Muestra como la responsabilidad por falla es el título más antiguo de responsabilidad, en los siguientes términos: "La responsabilidad por falta o falla del servicio, hoy entendida como responsabilidad por funcionamiento anormal, o también como inactividad de la administración, ha sido el más antiguo y utilizado fundamento de la responsabilidad administrativa, al punto que ha constituido en los sistemas que siguen el modelo francés el régimen de derecho común en la materia, y fue la especie más importante de las desarrolladas por la jurisprudencia colombiana, al menos a partir de 1964". Tenemos que decir esos sí, que la responsabilidad por falla ha sido la más tradicional en el Derecho Colombiano, pero no el más antiguo, porque fue la responsabilidad objetiva por expropiación, la primera forma de responsabilidad administrativa en Colombia.

3 DEPUIS, Georges y OTROS. Droit Administratif, novena edición, Paris, Francia, Armand Colin, 2004, p.56o, muestra como las conclusiones del Comisario de Gobierno Laferriere en el Fallo Laumonier- Carriol del Tribunal de Conflictos de 1877, dejan ver la distinción que existía entre la falta personal revelada en un hombre con sus debilidades, sus pasiones y su imprudencias, de la falta o falla del servicio, en donde se mostraba a un administrador, más o menos sujeto a error.

4 PAILleT, Michel. La Responsabilidad Administrativa, Bogotá, Colombia, Universidad Externado de Colombia, 2001, p.114: "el hecho del servicio es aquel que es indisociable del funcionamiento de la máquina administrativa tomada en su globalidad, de suerte que no puede imputarse a tal o cual agente tomado en forma individual, sino al sujeto de derecho que institucionaliza este conjunto de estructura y de agentes". 
En efecto, cuando se hace referencia a la responsabilidad por falla, es necesario probar la misma, lo cual implica demostrar que la administración actuó de manera contraria a la regularidad administrativa, que lo hizo de manera ilegal( Paillet, 2001, p. 147)5, contrariando postulados de buen servicio público o adecuada función administrativa; lo que significa, que la responsabilidad subjetiva comporta un sinnúmero de circunstancias que la determinan 6 , y de esta manera, es preciso indicar que la doctrina tradicional planteada por PAUL DUEZ, en el sentido que la anormalidad en el actuar de la administración se evidencia en que la misma actuó mal, tardíamente o no actuó, debe ser superada y hablarse que la existencia de actuaciones irregulares de las entidades públicas; lo cual implica, la posibilidad de extender los eventos de falla del servicio, por cuanto en la irregularidad es posible involucrar toda actuación de las personas jurídicas públicas, que se aleje del buen servicio, siempre que se identifiquen parámetros mínimos de correcta actividad administrativa (Foillard, 2004, p. 378) ${ }^{7}$.

5 IBIDEM p.147: "No es raro en doctrina que la culpa del servicio se entienda como un comportamiento contrario a las normas que gobiernan el funcionamiento de la administración, en todo caso con un abanico de aproximaciones, que la sitúan a la vez como una omisión o inobservancia de las leyes del servicio, como sinónimo de anormalidad o aún más como la violación de una obligación administrativa”.

6 Aunque es preciso aclarar, que no siempre que se incurra en falla del servicio, la actuación es ilegal, ya que en eventos como los hechos administrativos, puede ocurrir que no se esté violando una norma jurídica superior y sin embargo se puede tornar irregular; por el contrario, al existir una ilegalidad que genere un perjuicio, se está siempre en presencia de falla del servicio, porque si la actuación es ilegal, configura una irregularidad de la actividad administrativa.

7 FOILLARD, PHILIPPE. Droit Administratif, Orleans, Paradigme Publications Universitaires, 2004, p. 378 : «La faute peut etre un acte juridique (individuel ou réglementaire), une opération matérielle, un mauvais fonctionnement du service, un retard, une maladresse, une négligence... Elle peut résulter d'une action positive ou d'une inaction du service, d'une abstention (carence d'une autorité de police par exemple)».
Pero es en la sentencia Pelletier, donde en nuestro parecer se reconoce por primera vez la falla del servicio y no en otras decisiones como la Tomaso Grecco, según lo indican algunos doctrinantes (Saavedra, 2005, p. 241) ${ }^{8}$. En efecto, cuando dicha providencia hace alusión a la culpa personal y a la culpa del servicio, lo que está dejando ver es la existencia de actuaciones irregulares atribuibles al particular o a la administración, constitutivas de falta o falla del servicio según el caso, pero que por ser el Tribunal de Conflictos el que hace los pronunciamientos en dicha sentencia, solo se refirió a la asignación de competencia, teniendo en cuenta la atribución o imputación de responsabilidad (Saavedra, 2005, p. 235) .

El Consejo de Estado Francés en la decisión Tomaso-Grecco, hizo pronunciamiento de fondo sobre la falla del servicio, no como simple determinación del juez competente para conocer de un asunto, con fundamento en la clase de culpa, que fue lo realizado en el pronunciamiento Pelletier, es decir, la culpa personal y la culpa del servicio. Lo anterior es así, porque en dicha providencia se exoneró de responsabilidad a la administración, al no determinarse la existencia de falla atribuible a la misma, en el sentido que no existió prueba de la irregularidad en la actuación (Long, 2000, p. 8) ${ }^{10}$.

8 SAAVEDRA BECERRA, RAMIRO. La Responsabilidad Extracontractual de la Administración pública, obra citada, p.241. Quien es partidario de optar por criterios técnicos para determinar el buen funcionamiento administrativo, en el sentido de establecer estándares mínimos de funcionamiento aceptable de la administración.

9 IBIDEM, p. 235, aludiendo además a la sentencia Auxerre

10 LONG, MARCEAu. Los Grandes Fallos de la Jurisprudencia Administrativa Francesa, Bogotá, Ediciones Librería del Profesional, 2000, p.8, al referirse al espíritu del fallo Pelletier expresa: "La culpa personal es concebida como aquella que se desprende tan completamente del servicio que el juez ordinario puede constatarla, sin por ello entrar a apreciar el funcionamiento mismo de la administración. La falta del servicio al contrario es un hecho del agente tan ligado al servicio que su apreciación por parte del juez común automáticamente implica un apreciación del funcionamiento del servicio". Y si en la falta del servicio, lo que se hace es una 
Significa lo anterior, que al hablarse de falla del servicio, es preciso indicar que se debe probar la actuación irregular de la entidad pública, en los términos analizados en acápites anteriores de vulneración del buen servicio público y así determinar el título de imputación subjetivo de responsabilidad al Estado, que en el sistema francés se evidencia aún en casos de la actividad médica, cuando se generan errores en los procedimientos ${ }^{11}$ a pesar que en algunos eventos se puede estar frente a responsabilidad objetiva o falla presunta ${ }^{12}$.

\section{LA FALLA PROBADA DEL SERVICIO, EL PRINCIPAL CRITERIO DE RESPONSABILIDAD EN EL ORDENAMIENTO JURÍDICO COLOMBIANO}

En el derecho colombiano, la falla probada se ha constituido en el título de imputación de responsabilidad por excelencia, en la medida que las actuaciones irregulares de la administración, han constituido el fundamento tradicional de responsabilidad del Estado; en efecto, si se analiza la jurisprudencia del Consejo de Estado, esta ha sido la mayor expresión de responsabilidad administrativa, a pesar de que la responsabilidad objetiva es de más vieja data dentro de nuestro

apreciación del funcionamiento del mismo, significa que se realizan verificaciones y valoraciones de la actuación de la administración, que no es otra cosa que determinar si existió falla en el servicio público.

11 C. E. Francés, 10 de febrero de 1905, Tomaso Grecco, Rec. 139, conluc Comisario Romieu, expresa: "Considerando que de la instrucción no se desprende ni que el balazo que hirió al señor Grecco haya sido disparado por el policía Mayrigue ni que el accidente que sufrió el actor, pueda atribuirse a una falla del servicio atribuible a la administración; que en consecuencia, no asiste ningún derecho al señor Grecco para demandar la anulación de la decisión por la cual se denegó la atribución de una indemnización."

12 C.E. Francés Ass 10 de abril de 1992, Esposos V., Rec. 171, conclu. Legal. Responsabilidad por servicios médicos y quirúrgicos; En LONG, Marceau. Grandes fallos de la jurisprudencia administrativa francesa, obra citada, p.613. sistema jurídico (Morand-Deviller, Trad. Rincón y Peláez, 2010, p. 835) ${ }^{13}$.

De la misma manera que la concepción clásica francesa de la responsabilidad por falla, en el ordenamiento nacional, se han consagrado en principio como modalidades de ésta, lo eventos en que la administración no ha actuado, lo ha hecho tardíamente, o la actuación ha sido anómala. Lo anterior significa, que la actividad del Estado en este título de imputación de responsabilidad, se enmarca en conductas positivas como en los casos en que la administración ha actuado mal y en conductas omisivas para las circunstancias en que no haya actuado o la actuación ha sido tardía.

La jurisprudencia del Consejo de Estado desde sus inicios ${ }^{14}$, ha sido clara en contemplar las formas de falla en el servicio, a partir de los criterios tradicionales de responsabilidad subjetiva, para identificar este título de imputación, donde las omisiones administrativas por ejemplo, han dado lugar a atribuciones de responsabilidad $e$ indemnización de perjuicios, como consecuencia del no actuar de la administración ${ }^{15}$.

Pero es el actuar de la administración, el que ha caracterizado y determinado la noción de

13 La jurisprudencia francesa ha hablado de responsabilidad objetiva en asuntos médicos, en casos de transfusión sanguínea por ejemplo, consignada en: C.E., 26 de mayo de 1995 "M. Jouan y Consorts N'Guyen". Tomado de MORAND-DEVILLER, JACQUELINE. Curso de Derecho administrativo, traducción de Zoraida Rincón Ardila y Juan Carlos Pelaez, Universidad Externado de Colombia, Bogotá 2010. p.835.

14 La responsabilidad objetiva del Estado se contempla desde la Constitución del Estado de Cundinamarca de 1811, cuando se determinó la obligación de la administración de indemnizar perjuicios en casos de expropiación.

15 La competencia del Consejo de Estado para conocer de asuntos de responsabilidad es relativamente reciente, pues data del año de 1964, ya que antes y a pesar de la existencia de la jurisdicción contencioso administrativa desde 1913, se estableció con la Ley 130 de dicho año, que era la jurisdicción ordinaria la que conocía de dichos conflictos. 
falla del servicio, porque la jurisprudencia del Consejo de Estado ha seguido este criterio, sin desconocer que lo que identifica la responsabilidad subjetiva es que la actuación sea irregular (López, 1997, p.146) ${ }^{16}$, en las diversas modalidades que existen, porque es preciso indicar, que este término tiene una gran amplitud y se puede identificar en un sinnúmero de actuaciones de los órganos del Estado ${ }^{17}$; circunstancia que nos lleva a alejarnos de algún criterio del Consejo de Estado Colombiano, que parece adoptar sin mayores reparos la noción

16 C. E. Sala de lo Contencioso Administrativo, sentencia del 17 de noviembre de 1967, C.P. Gabriel Rojas Arbeláez, actor Alfonso Salazar y otros, dijo: "Se ha alegado por la parte demandada que solo después de la vigencia del Decreto de 1964 es procedente reconocer perjuicios por omisión del poder público, puesto que solo en este estatuto esa causal se consagró, expresamente, y que en consecuencia debe absolverse a la Nación. La afirmación carece de exactitud y considerándolo así, la sala de lo contencioso administrativo profirió la sentencia del 7 de mayo de 1963, expediente No 412, actores María Elena Umaña y otros, sentencia que por la causal de omisión, resultaron condenados a pagar indemnizaciones los municipios de Barranquilla y Bogotá respectivamente". Tomado de LOPEZ MORALEZ, JAIRO. La Responsabilidad Patrimonial del Estado, tomo I Ediciones Doctrina y Ley Ltda, Bogotá 1997, p.146

17 C.E. Sala de lo Contencioso Administrativo, Sección tercera, sentencia de octubre 20 de 1995, C.P. Jesús María Carrillo Ballesteros, confirma que el criterio para determinar la existencia de falla del servicio, es la actuación irregular de la administración cuando dice: "Si bien es cierto que el daño que sufrió el conscripto, ocurrió cuando adelantaba labores de la actividad castrense rebasó los límites del riesgo que en la tarea de guardianes de la vida honra y bienes de los ciudadanos tienen que soportar, mas cuando para este tipo de misiones, no aparece demostrado por la administración que le facilitó los medios suficientes para que llevara a cabo con la debida seguridad para su integridad personal, la tarea que se le concedió, como tampoco la misma entidad demostró que el lesionado tuviese destreza para escalar a la altura que lo hizo, sin comprometer la responsabilidad personal. Así las cosas, como en el caso sub-examine, se evidencia que la administración incumplió con la obligación de retornar en similares condiciones de salud a las que tenía cuando ingresó ROBINSON CARRILLO MOLINARES, a prestar el servicio militar obligatorio". clásica francesa, a que hicimos referencia en acápite anterior ${ }^{18}$.

De todas maneras, en la falla probada del servicio, es necesario demostrar la irregularidad en el actuar público, es decir, la culpabilidad de la administración, lo que significa, que además de acreditar la actuación, el daño y el nexo causal, es preciso evidenciar un Estado alejado de criterios de buen servicio público y por el contrario, se presenta como vulnerador de derechos ${ }^{19}$.

18 Así por ejemplo, la falla en el servicio por una actuación irregular de la administración, se encuentra en las actos ilegales de una autoridad pública, que son controvertidos a través de la acción de nulidad y restablecimiento del derecho y que de ser anulados, lo que dejan ver es una entidad alejada de la obligatoriedad de cumplir con el ordenamiento jurídico.

19 C.E. Sala de lo Contencioso Administrativo, Sección Tercera, expediente No.14.170, sentencia del 25 de febrero de 2005, M.P. Dr. Ramiro Saavedra Becerra, al referirse a las modalidades de la falla del servicio dijo: "No obstante que la norma constitucional hace énfasis en la existencia del daño antijurídico (se refiere al artículo 90 constitucional que consagra la responsabilidad del Estado por daño antijurídico) como fuente del derecho a obtener la reparación de perjuicios siempre que el mismo le sea imputable a una entidad estatal, dejando de lado el análisis de la conducta productora del hecho dañoso y su calificación como culposa o no, ello no significa que la responsabilidad patrimonial del Estado se haya tornado objetiva en términos absolutos, puesto que subsisten los diferentes regímenes de responsabilidad de imputación de responsabilidad al Estado que de tiempo atrás han elaborado tanto la doctrina como la jurisprudencia, entre ellos el de la tradicional falla del servicio, dentro de la cual la responsabilidad surge a partir de la comprobación de la existencia de tres elementos fundamentales: el daño antijurídico sufrido por el interesado, el deficiente funcionamiento del servicio, porque no funcionó cuando ha debido hacerlo, o lo hizo de manera tardía o equivocada, y finalmente, una relación de causalidad entre este último y el primero, es decir, la comprobación de que el daño se produjo como consecuencia de la falla del servicio". Paréntesis fuera del texto. 


\section{LA FALLA DEL SERVICIO EVIDENCIA DIVERSAS MODALIDADES}

Pero además de la falla probada, la jurisprudencia y la doctrina han identificado otras modalidades, dentro de las cuales se encuentran la anónima, la presunta y la falla relativa ${ }^{20}$.

\subsection{En la falla anónima la actuación es impersonal}

Esta modalidad de responsabilidad subjetiva, muestra una actuación irregular de la administración, que no puede atribuirse o imputarse a una persona física determinada, pero que se relaciona directamente con el servicio público o la actividad administrativa, es decir, que no se puede separar de ella; por esta razón, consideramos que esta tipología de obligación indemnizatoria de perjuicios, de alguna manera se aleja del concepto de falla o falta personal, por cuanto se contrapone a la misma, en la medida que en la falla personal, tanto la actuación como la responsabilidad son atribuibles a una persona determinada, con la salvedad, que en este caso por ser una irregularidad atribuible exclusivamente a quien incurrió en la actuación, la responsabilidad se imputa igualmente a la persona o sujeto activo; en cambio en la anónima, el acto es impersonal, pues no se puede identificar quien lo cometió (Ruíz, 2010, p. 8), pero sí determinar los hechos que sirven de fundamento a la asignación de responsabilidad ${ }^{21}$.

20 C.E. Sala de lo Contencioso Administrativo, Sección Tercera, expediente No. 10.494, sentencia del 29 de agosto de 1996, M.P. Daniel Suarez Hernández

21 T.C. Francés, Fallo Laumonier- Carriol, del 5 de mayo de 1877, hace referencia a la falla impersonal, que la podemos identificar con la falla anónima, así: "El criterio indicado por la jurisprudencia es el siguiente: si el acto dañino es impersonal, se deja ver a un administrador, a un mandatario del Estado, más o menos propenso al error, y no al hombre con sus debilidades, sus pasiones, sus imprudencias, el acto sigue siendo administrativo y no puede ser deferido a los tribunales ordinarios...". Tomado de MORAND - DEVILLER, JACQUELINE. Curso de Derecho Administrativo, obra citada, p.826; siendo preciso aclarar, que la falla

\subsection{La carga de la prueda identifica a la falla presunta}

La falla presunta por su parte, indica una actuación de la administración donde se presume la actuación irregular, es decir, se releva al particular de demostrar el funcionamiento anormal del servicio y en estas circunstancias, se considera que la entidad pública ha vulnerado principios de buen servicio público; siendo la actividad médica, la que constituye el campo de aplicación de dicha clase imputación ${ }^{22}$, que de todas maneras no ha sido uniforme en su concepción, pues ha ido desde la falla probada a la presunta, pasando por la variación del régimen probatorio utilizado para acreditar la actuación de la entidad pública y determinar la responsabilidad de la misma.

En efecto, el criterio de falla probada para atribuir responsabilidad por la actividad médica, sin distinguirla de las demás actuaciones de la administración, se ha utilizado desde tiempo atrás y aún hoy día se viene aplicando en esta clase especial de responsabilidad (Gil, 2010, p. 450$)^{23}$, con fundamento en que quien alega

anónima debe concebirse cuando la actuación no es atribuible a persona específica o determinada, pero la responsabilidad es de la administración a título de falla del servicio, pues hay casos en que siendo particularizada la conducta en una persona, puede no existir falla del servicio, sino falla personal.

22 C.E. Sala de lo Contencioso Administrativo, Sección Tercera, expediente 17.303, sentencia del 25 de febrero de 2009, M.P. Ruth Stella Correa, dice: "Es cierto que desde hace mucho tiempo la jurisprudencia de la corporación ha sostenido que la falla del servicio es anónima, para indicar que no se requiere establecer en el proceso quien fue el autor material del daño causado; pero esto no significa que no deba establecerse los hechos a partir de los cuales se pretende imputarle al mismo ese daño; por lo tanto, no era necesario que en este proceso se identificara a la persona que dio muerte al menor, pero para poder imputar ese hecho a la Nación, por haber sido causado por un agente a su servicio sí era necesario acreditar esa circunstancia".

23 GIL BOTERO, EnRIQUe. Responsabilidad Extracontractual del Estado, cuarta edición, Bogotá, Colombia, Ediciones Jurídicas Gustavo Ibañez, 2010, p.450, haciendo alusión a la sentencia del Consejo de Estado, 
la falla debe probarla y así, no se le reconoce al particular ninguna ventaja probatoria frente al ente público, como ocurre en las otras modalidades de responsabilidad médica ${ }^{24}$; pero la noción de falla probada en asuntos médicos, ha tenido fuertes reservas por ser tan especial y técnica la actividad medico asistencial y en esta medida, se han desarrollado criterios como el de la mejor posición de probar, para indicar, que la administración se encuentra frente al particular, en una posición más favorable para demostrar que su actuación se ajustó a los procedimientos técnico- científicos y que respecto de los cuales, al paciente o particular le queda muy difícil demostrar una actuación irregular de la misma ${ }^{25}$.

Sala de lo Contencioso Administrativo, del 24 de agosto de 1992, expediente 6754, muestra la falla presunta así: "A través de la falla presunta, se radicó en cabeza de la administración pública una presunción de hecho (iuris tantum o de hombre), la cual suponía prima -facie, en cada caso concreto, que el daño antijurídico en la actuación médico-hospitalaria, cuando se relacionaba con la prestación del servicio público de salud derivaba de la ocurrencia de una falla del servicio, motivo por el cual a la administración hospitalaria le correspondía acreditar su diligencia y cuidado, en los términos del artículo 604 del C.C., con el objetivo de destruir la presunción de culpa que obraba en su contra".

24 C.E. Sala de lo Contencioso Administrativo, Sección Tercera, expediente No.16.700, sentencia del 28 de enero de 2009, M.P. Mauricio Fajardo, indica: "La determinación del régimen jurídico aplicable en eventos donde se discute la responsabilidad extracontractual del Estado derivada del despliegue de actividades médicoasistenciales no ha sido pacífica en la jurisprudencia, como quiera que paralelamente a la postura que ha propendido por cimentar la responsabilidad estatal en estos casos sobre la falla presunta del servicio, ha tenido acogida igualmente, la posición- por lo demás prohijada por la sala en sus más recientes fallos- de acuerdo con la cual el título jurídico de imputación a tener en cuenta en los supuestos jurídicos en comento es el de la falla del servicio probada".

25 Ibídem, trae a colación algunas de sentencias proferidas por el Consejo de Estado, Sala de lo Contencioso Administrativo, Sección Tercera, que hacen alusión a la falla probada por servicios médico asistenciales, así: sentencia del 7 de diciembre de 2004, expediente 14.421, actor Ramón Fredy Millán y otros; sentencia del 3 de octubre de 2007, expediente 16.402, sentencia del 20 de febrero de 2008, expediente 16.739.
Significa lo anterior, que la noción de la mejor posición para probar, se constituye en un antecedente o sustento para la acreditación de la teoría de la falla presunta del servicio, en donde el particular iguala su posición frente a la administración en asuntos de responsabilidad médica, porque se le otorga la ventaja, de que no tiene que entrar a demostrar el funcionamiento irregular del servicio público, sino que este se presume, con fundamento en que la administración tiene una mejor capacidad probatoria; pero la exoneración de probar no es absoluta, ya que está en la obligación de demostrar la actuación de la entidad estatal, el daño y el nexo de causalidad (Gil, 2010, p. $448)^{26}$, en la medida, que cualquier imputación de responsabilidad administrativa, tiene que derivarse de un actuar de órgano público o de un particular que desarrolle servicio público o actividad administrativa.

Es lógico que en actividades médicoasistenciales, no se dé el mismo tratamiento probatorio al particular frente a la administración, ya que además de existir desventaja técnico-científica frente la entidad pública, hay una posición de inferioridad del particular en la prueba de las circunstancias que pueden rodear los acontecimientos que causan el perjuicio, en la medida que una intervención quirúrgica normalmente se realiza a puerta cerrada $y$ con la presencia exclusiva de los profesionales de la medicina que son los que causan los daños, que en ocasiones muestran una falla anónima de la administración, lo que impide que terceros puedan dar cuenta de los hechos y colaborar en la demostración de la actuación irregular; por tal razón, la jurisprudencia le ha

26 GIL BOTERO, ENRIQUE. Responsabilidad Extracontractual del Estado, cuarta edición, Bogotá, Ediciones Jurídicas Gustavo Ibáñez, 2010, p.448; quien además muestra, que es en la sentencia del 30 de julio de 1992, expediente 6897 M.P. Daniel Suarez, cuando el Consejo de Estado, asume el concepto de que en la actividad médica, la administración se encuentra en mejor posición para probar, ante un particular que no tienen en la generalidad de los casos los conocimientos científicos para acreditar una falla del servicio. 
dado al particular algún alivio en la obligación de probar la culpabilidad en estos $\operatorname{casos}^{27}$.

Por las anteriores circunstancias, el régimen probatorio en asuntos de actividad médica, dependiendo el título de imputación de responsabilidad que se utilice, ha sido manejado de forma diferente; así, de la obligación de demostrar la actuación irregular de la administración en los eventos de falla probada, se pasó a la denominada carga dinámica de la prueba, en donde la posición de la parte frente al asunto a probar, determina la obligación de aportar a la actuación contenciosa los elementos de juicio para acreditar los supuestos de hecho objeto de prueba; en el caso de la falla del servicio, hay que decir, que le corresponde al particular demostrar la actuación defectuosa del órgano del Estado, mientras que a la entidad pública le compete demostrar que actuó ajustada a la legalidad, a criterios de buen servicio público y una adecuada actuación administrativa ${ }^{28}$.

En algunos casos la jurisprudencia del Consejo de Estado ha identificado la falla presunta con

27 C.E. Sala de lo Contencioso Administrativo, sección tercera, sentencia del 24 de agosto de 1992, expediente 6754, M.P. Carlos Betancur Jaramillo, lo muestra de esta manera cuando expresa: "La exoneración de la carga de la prueba que implica la noción de falla presunta es apenas relativa, porque al actor le incumbe en tales casos probar como mínimo los supuestos que permiten la operancia de la presunción. Así, en el caso de que alguien alegare que resultó lesionado por una intervención quirúrgica inadecuada, deberá probar en términos generales, que se le prestó el servicio en tal fecha y que sufrió el daño cuya indemnización pretende."

28 C.E. Sala de lo Contencioso Administrativo, Sección Tercera, sentencia del 15 de junio de 2000, expediente 12.584, M.P. María Elena Giraldo, dijo: "Aceptada las dificultad que suele causarse en la prueba de la causalidad en materia medica, no resulta aventurado sostener que ante casos de difícil prueba se adopten criterios que aligeren la situación de la víctima, máxime si se tiene presente que, la dificultad en el hallazgo de una causalidad razonablemente cierta que permita formular el juicio de imputación, puede obedecer, precisamente, a la forma grupal de la prestación del servicio médico de salud...". la carga dinámica de la prueba ${ }^{29}$, lo cual no es correcto, por cuanto la carga dinámica de la prueba se diferencia de la falla presunta, en que la obligación de probar no es estática como ocurre en esta última, donde presumiendo la actuación irregular de la administración, le corresponde a la entidad pública prestadora del servicio médico asistencial, demostrar que actuó correctamente; por el contrario, existe obligación de probar tanto de la administración como del particular, dependiendo su posición frente al supuesto de hecho que se pretenda demostrar y así, quien tenga mejor condición de probar lo debe hacer, implicando esta circunstancia, la existencia de equilibrio y distribución de las cargas de prueba ${ }^{30}$.

Actualmente, el Consejo de Estado sin desconocer la existencia de los títulos de imputación de responsabilidad médica de falla probada, presunta y carga dinámica de la prueba, ha adoptado el criterio de las cosas hablan por sí solas o los llamados errores crasos, en los eventos de actuaciones irregulares de la administración

29 C.E. Sala de lo Contencioso Administrativo, Sección Tercera, sentencia del 10 de febrero de 2000, expediente 11.878, M.P. Alier Eduardo Hernández Henríquez, al referirse a la falla presunta, dijo que en relación con esta posición, reiterada por la jurisprudencia de esta Sala a partir de la expedición del fallo contenido en la sentencia del 30 de julio de 1992, del C.E., Sala de lo Contencioso Administrativo, Sección Tercera, expediente 6897, M.P. Daniel Suarez Hernández, la misma tiene origen en el principio de las cargas probatorias dinámicas, exigiéndosele a las entidades la obligación de probar que actuaron adecuadamente.

30 C.E. Sala de lo Contencioso Administrativa, Sección Tercera, sentencia del 10 de junio de 2004, expediente No. 25.416, M.P. Ricardo Hoyos Duque, cuando expresa: "En síntesis, puede afirmarse que, en muchos eventos, el demandante puede ser relevado por el juez de acreditar la falla del servicio médico en aplicación del principio de la carga dinámica de las pruebas o bien a través de una inversión de la carga de las mismas, en atención al alto grado de dificultad que representa para éste acreditar hechos de carácter científico o realizado en condiciones en la cuales únicamente el profesional médico tiene acceso a la información". 
que son evidentes y manifiestas ${ }^{31}$; por tal razón, se releva al particular de la prueba de la culpabilidad de la entidad pública, circunstancia que nos permite decir, que en el sistema jurídico colombiano se está abriendo paso la noción de responsabilidad objetiva en los casos de actuaciones médico asistenciales, porque solo corresponde demostrar la actuación que por su naturaleza es irregular, el daño y el nexo causal, pues se le ha eximido al actor de probar la culpabilidad o la falla; siendo extremadamente difícil para la administración probar que actuó adecuadamente, por cuanto el error es evidente, y entonces, tendrá que acudir a las eximentes de responsabilidad para librarse de la condena al reconocimiento y pago de perjuicios ${ }^{32}$.

Así, la noción de falla en el caso de responsabilidad médica, ha tenido variaciones de gran interés, que han dejado ver una actuación especial que amerita un tratamiento igualmente especial, en la atribución de responsabilidad por los daños causados como consecuencia de la misma, llevando a la necesidad de distinguir el acto médico en estricto sentido, que es el que está sujeto a los criterios de responsabilidad analizados, de los actos o actividades conexas al acto médico, que se rigen de manera expresa

31 C.E. Sala de lo Contencioso Administrativo, Sección Tercera, sentencia del 22 de marzo de 2001, expediente 13.666, M.P. Ricardo Hoyos Duque: "Más recientemente, la Sala ha considerado que la presunción de falla en los casos de responsabilidad médica se deriva de la aplicación de la teoría de la carga dinámica de las pruebas y por lo tanto, dicha presunción no debe ser aplicada de manera general sino que en cada caso el juez debe establecer cuál de las partes está en mejores condiciones de probar la falla o su ausencia".

32 C.E. Sala de lo Contencioso Administrativo, Sección tercera, sentencia del 19 de agosto de 2009, expediente 18.364, M.P. Enrique Gil Botero, lo consigna así "Se configuró, en el caso concreto, lo que la doctrina alemana ha denominado "error craso"... todo lo anterior con fundamento en las reglas de la experiencia científica, objetiva y estadística, que permiten inferir sin requerir un conocimiento especializado sobre la materia, que el yerro cometido se produjo por una equivocada convicción que pudo ser fácilmente superada, lo cual hubiera evitado la producción del evento dañoso". para la imputación de responsabilidad, por la noción de falla probada del servicio ${ }^{33}$.

\subsection{En la falla relativa existe ausencia de responsabilidad}

La falla relativa por su parte, hace referencia a que a la administración se le aplica el principio general de derecho que expresa: nadie está obligado a lo imposible y así, una entidad pública no está conminada a realizar actuaciones que no se encuentre en capacidad de realizar; lo que significa, que si se llega a causar un daño ante la no actuación de la administración, la falla será relativa ${ }^{34}$.

Significa lo anterior, que no puede atribuírsele responsabilidad a la persona jurídica pública y obligarla a la indemnización de perjuicios, cuando los mismos son causados por la actuación de una entidad del Estado, a pesar de que ha actuado con la mayor diligencia, cuidado y utilización de todos los recursos con que cuenta, pero sin embargo el daño se produce de manera inevitable (Ruíz, 2010, p.12); lo cual evidencia que no existió una actuación irregular, por lo que en nuestro parecer se presenta una ausencia de responsabilidad, ya que todo daño que se causa no genera una obligación automática de reparación.

Por otra parte, es preciso indicar, que en la falla relativa nos encontramos frente a los conceptos de Estado ideal y Estado real, en cuanto a que si bien es cierto es obligación del Estado y de la administración proteger la vida, bienes y honra de los ciudadanos ${ }^{35}$, dicha

33 La jurisprudencia administrativa francesa, ha previsto la responsabilidad objetiva del Estado en asuntos de actividad médica, como en los casos de daños causados en centros públicos de transfusión sanguínea. C.E. fallo del 26 de mayo de 1995, M, Jouan y Consorts N'Guyen. Tomado de MORAND - DEVILLER, JACQUELINE. Curso de Derecho Administrativo, obra citada, p. 835.

34 Ver C.E. Sala de lo Contencioso Administrativo, Sección Tercera, sentencia del 28 de abril de 2010, expediente 18.574, M.P. Ruth Stella Correa.

35 C.E. Sala de lo Contencioso Administrativo, Sección Tercera, sentencia del 30 de noviembre de 2006, 
obligación se relativiza por las condiciones materiales que se presentan en el País, que hace que en ocasiones las autoridades públicas no puedan cumplir adecuadamente con la obligación constitucional de protección, sin que signifique que han actuado irregularmente; por el contrario, se puede evidenciar de alguna manera que la actuación fue perfectamente diligente y sin embargo se genera el perjuicio, pero este no es indemnizable, al no existir responsabilidad atribuible al Estado ${ }^{36}$.

Consideramos entonces, que en los eventos antes planteados, más que existir una falla relativa de del servicio, hay es una actuación de la administración ajustada a parámetros de regularidad o legalidad y en estas circunstancias, se presenta una ausencia de responsabilidad del Estado, por cuanto el actuar de la entidad pública no es el que produce el daño $y$ entonces, no se contiene el primer requisito de toda forma de imputación de responsabilidad estatal, como es la actuación de un órgano público o particular que cumpla funciones públicas que produce un daño.

\section{LA FALLA DEL SERVICIO EN EL SISTEMA JURÍDICO ESPAÑOL, HA CEDIDO PASO A LA RESPONSABILIDAD OBJETIVA}

En el sistema jurídico español, la noción de falla no ha sido de gran tradición, por cuanto las actuaciones irregulares de la administración, no se han constituido en el principal título de imputación de responsabilidad administrativa,

expediente 16.626, M.P. Alier Hernández Enríquez, quien además la presenta de la siguiente manera: "Se le exige al Estado la utilización adecuada de todos los medios de que está provisto, en orden a cumplir el cometido constitucional en el caso concreto; si el daño se produce por su incuria en el empleo de tales medios, surgirá su obligación resarcitoria; si el daño ocurre pese a su diligencia no quedará comprometida su responsabilidad"

36 Es preciso indicar, que no todo daño es indemnizable, pues para serlo se debe haber roto el principio de equilibrio frente a las cargas públicas. ya que los criterio de responsabilidad objetiva son los que han primado en la asignación de responsabilidad; pero dentro de las diversas modalidades de falla del servicio, es la probada la que tiene mayor sustento y aplicación, ya que es necesario demostrar no solamente la actuación, el daño y el nexo causal, sino también la irregularidad o culpabilidad de la entidad pública.

En efecto, de vieja data el sistema jurídico español ha considerado la responsabilidad por falla como título de imputación para obligar a la administración a indemnizar perjuicios, con fundamento en la consagración que hace el artículo 1902 del Código Civili37, en conexión con el artículo 1903 del mismo Código ${ }^{38}$; normas que de una $\mathrm{u}$ otra forma involucran la actuación irregular de quien incurre en el hecho, cuando las disposiciones civiles hablan de la culpabilidad en el sujeto de la actuación.

En efecto, la noción de culpa originada en el derecho privado así sea de manera poco aceptada, ha identificado la responsabilidad subjetiva en el Estado Español, por cuanto, la imputación de esta clase de responsabilidad se referencia en los principios del Código Civil que hacen alusión a la responsabilidad civil extracontractual; lo que significa, que es el legislador en la regulación de las consecuencias

37 C.E. Sala de lo Contencioso Administrativo, Sección tercera, sentencia del 4 de diciembre de 2007, expediente 16.894, M.P. Enrique Gil Botero, expresó: "La relatividad de la falla, en estos eventos, se relaciona con la imposibilidad de exigir de manera absoluta a la organización estatal, prevenir cualquier tipo de daño o resultado antijurídico, como quiera que el estado no se encuentra en brindar una protección personalizada a cada individuo que conforma el conglomerado social".

38 El artículo 1902 del Código Civil Español dice: "El que por acción u omisión cause daño a otro, interviniendo culpa o negligencia, está obligado a reparar el daño causado"; es te artículo consagra el principio general de derecho que sustenta la responsabilidad tanto pública como privada y que está previsto en el artículo 2341 del Código Civil de Colombia, que expresa:"El que ha cometido un delito o culpa, que ha inferido daño a otro, es obligado a la indemnización, sin perjuicio a la pena principal que la ley imponga por la culpa o el delito cometido". 
del actuar de los particulares, el que ha determinado el antecedente de la noción, con fundamento en criterios de responsabilidad civil; lo que llevó de alguna manera a determinar una fuerte tendencia de irresponsabilidad del Estado, por cuanto no respondía por el actuar de los funcionarios en ejercicio de las competencias o funciones asignadas a su cargo, ni siquiera con criterios de culpa en la elección o en la vigilancia ${ }^{39}$; en efecto, había que buscar primero la responsabilidad y la indemnización del perjuicio en quien incurrió en la actuación y luego sí, de manera subsidiaria en la administración, como se evidenció en la normas dictadas a partir de la Constitución de 1931.

Sin embargo, las nociones de responsabilidad civil aplicadas a la actividad administrativa, no resistieron una fuerte aplicación a la función de la administración pública, por cuanto los criterios de responsabilidad indirecta que son tradicionales en el derecho privado, como expresión de la obligación de seleccionar adecuadamente a los servidores o vigilar de manera eficiente a los mismos, no fueron de clara atribución en la actividad de las administraciones públicas españolas, ya que no se presentó distinción entre la persona que produce directamente el daño y la entidad pública, sino que existía unidad entre una y otra, por tal razón la actuación se considera atribuida a la persona jurídica pública, en el entendido que la misma sea en ejercicio de actividad administrativa o de servicio público (Martín, 2006, pp. 420 - 421)

39 Por su parte el artículo 1903 del Código Civil de España consagra: "La obligación que impone el artículo anterior es exigible, no sólo por los actos $u$ omisiones propios, sino por los de aquellas personas de quienes se debe responder...", aquí se contempla tanto la responsabilidad directa como la responsabilidad indirecta, es decir, por el hecho propio y por el hecho del tercero, que el sistema jurídico colombiano prescribe además del artículo 2341, en los artículos 2347 y 2349 del Código Civil.

40 MARTín MATEO, RAmón. Manual de Derecho Administrativo, 25 a edición, Thomson Aranzadi, Navarra España, 2006, pp. 420 y 421, quien da cuenta, que con el predominio de la responsabilidad por culpa del Código Civil, el resultado fue descargar y además, porque el artículo 1903 del Código Civil consagró únicamente la responsabilidad del Estado por el hecho ajeno, en los casos de de actuación de un agente especial (Parejo y otros, 1998, p. 684) $)^{41}$, que no encontró mayor eco en la jurisprudencia española para atribuir responsabilidad administrativa, a pesar de que esté artículo 1903 remitía a lo preceptuado en el artículo 1902, que trata de la responsabilidad por el hecho propio (Mir, 2000, p. 37) ${ }^{42}$.

Así la noción de falla del servicio no se sustente en la culpa por el hecho ajeno del derecho privado, sí tiene algún antecedente en la misma, como se muestra en la regulación que hicieron el artículo 41 de la Constitución de 1931 y la Ley Municipal de 1935, que consagraron la responsabilidad indirecta de la administración;

a la administración de toda responsabilidad civil, teniendo en cuenta que los tribunales para los actos ejecutados por los empleados en el desempeño de las funciones propias de su cargo, no cabía suponer de parte del Estado culpa, ni siquiera negligencia, en la designación de sus agentes, sino, por el contrario, la previsión humanamente posible.

41 Con PAREJO ALFONSO, LUCIANO y OTROS. Manual de DerechoAdministrativo, volumenI, $5^{\text {a }}$ edición, Barcelona, España, Editorial Ariel, 1998, p.684, quien lo evidencia de esta manera: "Si la responsabilidad extracontractual civil descansa sobre la culpa como criterio de ilicitud del daño o perjuicio y en la excepcionalidad de la imputación de la misma por hecho de tercero (por culpa in vigilando o in eligendo), la evolución que conduce a la responsabilidad administrativa perfila ésta justamente sobre las características opuestas: la responsabilidad de la Administración pública por daños o perjuicios causados por el funcionamiento de los servicios públicos de su titularidad es directa (se atribuyen siempre a la propia organización administrativa titular del servicio las consecuencias de los hechos de sus agentes) y objetiva no requiere el concurso de culpa".

42 MARTÍN REBOLLO, Luis. Ayer y hoy de la Responsabilidad Patrimonial de las Administraciones Públicas: un balance y tres reflexiones, En: RAP, número 150 , septiembre - diciembre de 1999, p.330, quien da cuenta que el agente especial era un extraño personaje que nadie conocía, lo que nos permite afirmar, que la atribución de responsabilidad a la administración con su actuar fue muy escaza. Tomado de MIR PUIGPELAT, ORIOL. La Responsabilidad Patrimonial de la Administración Pública -hacia un nuevos sistema-, Editorial Civitas, Madrid España, 2000, p.37 
de todas maneras, es preciso indicar, que el antecedente de la misma se debe buscar con mayor fuerza de argumentación, en el criterio de actuación irregular de las administraciones públicas, pero por el hecho propio, que igualmente consagra la legislación civil española, en donde se identifica quien comete el acto y la institución administrativa pública; porque al contrario de lo que indica alguna parte de la doctrina española (Mir, 2000, p. 37), no se puede desconocer el antecedente de la regulación civil, en la asignación de responsabilidad al Estado por actuaciones irregulares de la administración.

De todas formas, la responsabilidad por falla en el Derecho Español, además de tener antecedentes en la regulación, civil, se fundamenta en los criterios clásicos franceses de responsabilidad de la falla del servicio, es decir, en que el servicio funcionó defectuosamente, no funcionó o lo hizo en forma tardía, todo enmarcado en la actuación irregular de la administración, así se derive de una falla o falta del servicio personal del agente, porque en este sistema jurídico, a diferencia de los galos, no se concibe de la misma manera la distinción entre falta o falla personal de la falta o falla del servicio, pues en uno y otro evento debe responder la administración, teniendo en cuenta que se está en cumplimiento de función administrativa y el servidor y el ente público conforman unidad (Parejo y otros, 1998, p. 684).

No se puede desconocer entonces, que en el sistema jurídico español, la falla del servicio es un título de imputación que se identifica con la noción de irregularidad en la actuación administrativa y que en algunos eventos, se puede enmarcar dentro de la ilegalidad de la función de las administraciones públicas, cuando con los hechos o las omisiones administrativas se viola el principio de legalidad, que debe asistir a toda la actividad de las personas jurídicas públicas inmersas en el Estado de Derecho o Social de Derecho (Parada, 2004, p. 637) ${ }^{43}$.

43 PARADA, RAmón. Derecho Administrativo parte General, decimo quinta edición, Madrid España, Marial Pons, 2004, p.637. Muestra como la doctrina y

\section{CONCLUSIONES}

La responsabilidad del Estado se ha manejado entre los dos títulos de imputación de responsabilidad tradicionales, como son la objetiva o sin falla y la subjetiva o por falla; siendo esta última la de mayor tradición en el sistema jurídico colombiano, porque es la actuación irregular de la administración la que en la mayoría de los casos genera perjuicios indemnizables a los particulares.

La responsabilidad por falla del servicio tiene su origen en el Derecho Administrativo Francés, con algunas decisiones del Tribunal de Conflictos y del Consejo de Estado, lo que ha determinado que sea de clara preponderancia jurisprudencial; lo que significa, que han sido las providencias de la jurisdicción contencioso administrativa la que le imprimen identidad.

En el derecho colombiano, la responsabilidad por falla, no se ha alejado de la concepción francesa, al identificar la misma, en que la administración actuó mal, tardíamente o no actuó; pero que con las sentencias de la jurisdicción contencioso administrativa, se han ido afianzado los criterios de irregularidad o anormalidad en la actuación como fuente de responsabilidad administrativa por falla del servicio, ante las limitaciones que presenta la teoría clásica francesa.

La responsabilidad subjetiva no se concreta únicamente con el criterio de falla probada, sino que existen otras modalidades como la presunta, la anónima o la falla relativa, en donde cada una de ellas mantiene su identidad y sus características propias. En efecto, la doctrina en la mayoría de los casos identifica la falla con la prueba de la

\footnotetext{
la jurisprudencia española ha ido al límite en asuntos de responsabilidad administrativa, al no exigir de la administración la obligación de indemnizar en los casos de falta personal o del servicio, teniendo en cuenta que el funcionario se encuentra integrado a la organización administrativa y actúa desempeñando las funciones que en ella tiene encomendadas; trayendo a colación las sentencias del Tribunal Supremo de 20 de marzo de 1977, 25 de febrero y 11 de junio de 1981 y 23 de septiembre de 1982.
} 
misma, lo cual es un error, porque en los eventos de la falla presunta, lo que especifica la misma, es la presunción de existencia.

En el Derecho Español al contrario de lo que ocurre en Colombia, la falla del servicio no es el título de imputación de mayor tradición, ya que es la responsabilidad objetiva la que tiene una regulación y desarrollo de significativa amplitud, lo que ha llevado a que alguna parte de la doctrina diga, que en el sistema español, lo que existe es una obligación general de responsabilidad, lo cual en nuestro parecer no es cierto, porque como se analizó anteriormente, la falla del servicio no es desconocida en este ordenamiento, frente funcionamiento anormal de los servicios públicos.

\section{BIBLIOGRAFÍA}

Alpa, Guido. (1999). Trattato de diritto civile, tomo IV, la responsabilitá civile, Dot. A Giufre, S.P.A. Milano.

Benoit, Francis Paul. (1957).Essai sur les conditions de la responsablité en droit public et privé, JCP. Paris.

Casino Rubio, Miguel. (1998). Responsabilidad Civil de la Administración y Delito, Marcial Pons, Madrid.

Chapus, RENE. (1957). Responsabilité publique et responsabilité privée, les influences réciproques des jurisprudences administrative et judicial, 2a ed. L.G.D.J., Paris 1957

Chapus, Rene. (1995) Droit Administratif General T. I., Paris Monchrestien.

Deguergue, MARYSE. (1994). Jurisprudence et doctrine dans l'élaboration du droit de la responsabilité administrative, L.G.D.J., Paris.

Díez Picazo, LuIs. (1962). El problema de acumulación de responsabilidad contractual y la responsabilidad delictiva en el derecho español,
Revista del Instituto de Derecho Comparado, núm 19, julio-diciembre.

Depuis, Georges y otros. (2004). Droit Administratif, novena edición, Paris, Francia, Armand Colin, 2004,

Folllard, PhilipPe. (2004). Droit Administratif, Orleans, Paradigme Publications Universitaires.

Forsthoff, Ernest. (1958). Tratado de Derecho administrativo, Instituto de estudios políticos, Madrid.

Gil Botero, EnRiQue. (2010). Responsabilidad Extracontractual del Estado, cuarta edición, Bogotá, Colombia, Ediciones Jurídicas Gustavo Ibañez..

Henao, Juan Carlos. (1998). El daño, Universidad Externado de Colombia, Bogotá.

Le Tournau, Philippe. (2004). La responsabilidad civil, Editorial Legis, Bogotá.

Long, Marceau. (2000). Los Grandes Fallos de la Jurisprudencia Administrativa Francesa, Bogotá, Ediciones Librería del Profesional, 2000

Lopez Moralez, Jairo. (1997). La responsabilidad Patrimonial del Estado, tomo I Ediciones Doctrina y Ley Ltda, Bogotá.

LopezMoralEZ, JaIRO. (1996). La responsabilidad del Estado por error judicial Ediciones Doctrina y Ley Ltda, Bogotá.

Martín Mateo, RAmón. (2006). Manual de Derecho Administrativo, 25a edición, Thomson Aranzadi, Navarra España.

Martín Rebollo, Luis. (1999). Ayer y hoy de la Responsabilidad Patrimonial de las Administraciones Públicas: un balance y tres reflexiones, En: RAP, número 150, septiembre - diciembre.

Mir Puigpelat, Oriol. (2000). La Responsabilidad Patrimonial de la Administración Pública -hacia un nuevos sistema-, Editorial Civitas, Madrid España. 
Morand-Deviller, Jacqueline. (2010). Curso de Derecho administrativo, traducción de Zoraida Rincón Ardila y Juan Carlos Peláez, Universidad Externado de Colombia, Bogotá.

Paillet, Michel. (2001). La Responsabilidad Administrativa, Bogotá, Colombia, Universidad Externado de Colombia.

PARADA, RAMÓN. (2004). Derecho Administrativo parte General, decimo quinta edición, Madrid España, Marial Pons.

Parejo Alfonso, Luciano y otros. (1998) Manual de Derecho Administrativo, volumen I, $5^{\text {a }}$ edición, Barcelona, España, Editorial Ariel, 1998.

Parejo Alfonso, Luciano. (2008)Lecciones de Derecho Administrativo, Tiran lo Blanch, Valencia.

Ruiz OJedA, Wilson. (2010) Responsabilidad del Estado y sus Regímenes, Bogotá, Colombia, Ecoe Ediciones.

SaAvedra Becerra, Ramiro. (2005). La Responsabilidad Extracontractual de la Administración Pública, tercera reimpresión, Bogotá Colombia, Ediciones Jurídicas Gustavo Ibáñez.

Schmidt-Assmann, EBERHARD. (2003). La teoría del Derecho Administrativo como Sistema. Marcial Pons, Madrid.

Sánchez Goyanes, ENRIQUE y otros. (1997). Manual de Derecho Administrativo, Editorial Constitución y Leyes (Colex), Madrid.
Soro Mateo, Blanca. (2006).Terrorismo y responsabilidad patrimonial de las administraciones públicas, en: Anales de Derecho, Universidad de Murcia, número 24. Murcia.

TAMAYO JARAmillo, Javier. (1997).La Responsabilidad del Estado, el daño antijurídico, el riesgo excepcional y las actividades peligrosas, Editorial Temis, Bogotá 1997

TAMAYO Jaramillo, Javier. (2000) La Responsabilidad del Estado. Editorial Temis S.A., Bogotá.

TAMAYO JARAMILlO, JAVIER. (2007)Tratado de responsabilidad civil, T.I., Editorial Temis, Bogotá.

Truchet, DiDIER. (2008). Droit administratif, thémis droif, Paris.

Vedel, Georges. (1980). Derecho Administrativo, traducción de la $6^{a}$ edición francesa por Juan Rincón Jurado, Editorial Aguilar, Madrid.

Vedel, Georges. (1980) Derecho Administrativo, Aguilar, Madrid España 1980

Vidal Perdomo, Jaime. (1997). Derecho Administrativo, undécima edición, Editorial Temis, Bogotá.

Villar Rojas, Francisco JosÉ. (1986). La Responsabilidad de las Administraciones Sanitarias: Fundamento y límites, Praxis, Barcelona.

Viney, Geneviéve. (2007). Traité de Droit Civil, introduction a la responsabilité, Universidad Externado de Colombia, Bogotá. 